EPJ Web of Conferences 98, 06001 (2015)

DOI: $10.1051 /$ epjconf/ 20159806001

(C) Owned by the authors, published by EDP Sciences - SIF, 2015

\title{
Economics of electricity
}

\author{
G. ERdmann(*) \\ Berlin University of Technology - TU 10587 Berlin, Germany
}

\begin{abstract}
Summary. - The following text is an introduction into the economic theory of electricity supply and demand. The basic approach of economics has to reflect the physical peculiarities of electric power that is based on the directed movement of electrons from the minus pole to the plus pole of a voltage source. The regular grid supply of electricity is characterized by a largely constant frequency and voltage. Thus, from a physical point of view electricity is a homogeneous product. But from an economic point of view, electricity is not homogeneous. Wholesale electricity prices show significant fluctuations over time and between regions, because this product is not storable (in relevant quantities) and there may be bottlenecks in the transmission and distribution grids. The associated non-homogeneity is the starting point of the economic analysis of electricity markets.
\end{abstract}

\section{1. - Electricity generation}

As with many other goods and services, the demand for electricity is subject to daily, weekly and seasonal fluctuations (see fig. 1). Electricity demand in winter periods is usually higher than in the summer periods. In the winter term it has daily peaks during the evening hours, while during the summer daily peaks occur at noon. At typical

$\left(^{*}\right)$ Chair for Energy Systems, TU berlin. E-mail: Georg.erdmann@tu-berlin.de

This is an Open Access article distributed under the terms of the Creative Commons Attribution License 4.0, which permits unrestricted use, distribution, and reproduction in any medium, provided the original work is properly cited. 


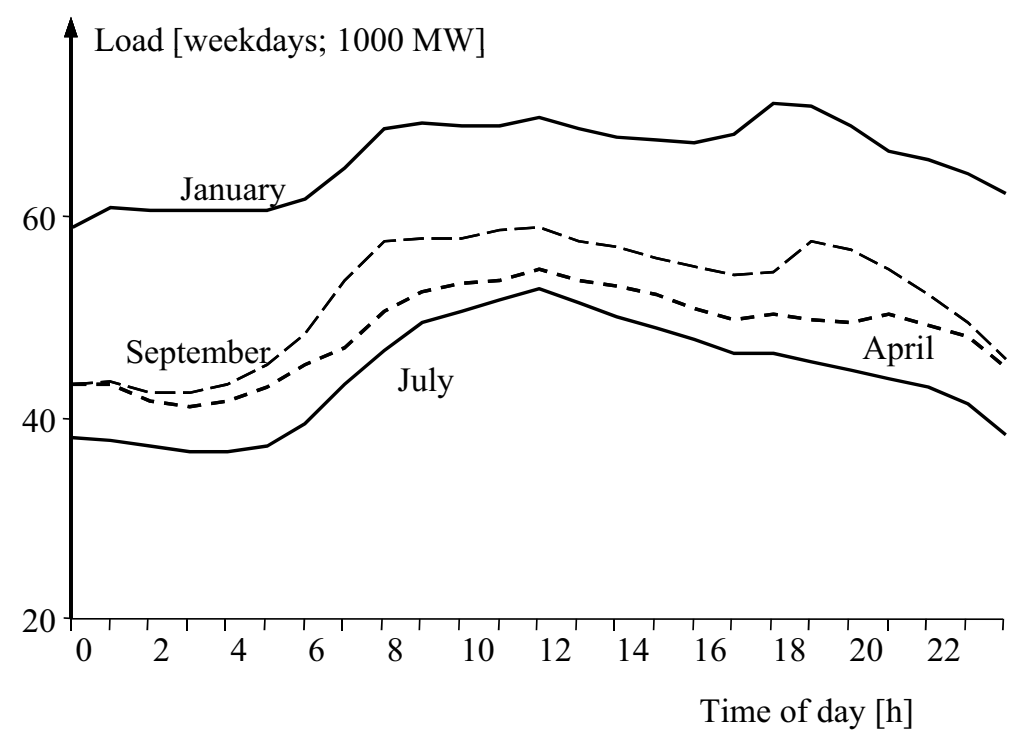

Fig. 1. - Daily electricity demand variations.

spring and autumn days the structure of the load profile is different again. The load curves shown in fig. 1 refer to northern regions. In southern regions the load may look quite different, due to a different role of electricity for heating and a higher electricity consumption for air conditioning.

In view of the demand fluctuations, electricity suppliers would ideally use the following strategies to match supply and demand:

- Storage of off-peak electricity for covering peak-load.

- Variation of supply quality, for example by interruptible load contracts with appropriate customers.

- Price differentiation with respect to time.

These options are used, particularly in the segment of industrial customers. The European Union requires all retailers to offer an electricity tariff, where the price per kilowatthour varies with time. Until today this variation is independent of the generation of wind and solar electricity generation but with growing shares of these technologies a more flexible tariff structure will be needed. Also due to missing large-scale electricity storage facilities $\left({ }^{1}\right)$ and so-called smart meters allowing flexible time-of-use tariffs or - more ambitious - real-time pricing $\left({ }^{2}\right)$ a full compensation of load fluctuations is not possible.

$\left({ }^{1}\right)$ At the present, a lithium battery with a mass of one $\mathrm{kg}$ can just store one $\mathrm{kWh}$ of electricity.

$\left(^{2}\right)$ In some sense electricity is still "too cheap to meter". This may change if intelligent meters (smart meters) become more economical. 
As a consequence of the non-storability of electricity and the minor role of load management measures, the generators must adjust their production in order to continuously synchronize supply and demand. How this task is accomplished today and how it is different from pre-liberalized markets is now discussed.

1`1. Power generation technologies. - Most power plants generate electricity according to the principle of magnetic induction. The electric side of such power plants consists of a stator (coil) and a rotor (rotating electromagnet). The generator produces alternating current with a frequency of 50 or 60 hertz and an electric voltage between 6 and 21 kilovolts. For the propulsion of the generator, kinetic energy is required, which can be supplied by a turbine using the heat from combustion. Alternative designs use hydropower and wind power. Another approach is to use electrochemical principles, e.g. photovoltaic cells and fuel cells. These devices produce direct current. The electricity must pass through an inverter in order to feed the power into the public AC grid.

- Steam turbine power plants are based on a thermal cycle. The heat from burning fossil fuels is used to transform water into high-temperature and high-pressure steam. The steam is fed to a turbine, where it expands and generates rotational energy, which drives the generator. The remaining energy dissipates through a steam condenser into the environment. With present technologies up to $46 \%$ of the thermal energy contained in the fuel can be converted into electricity. All fossil or nuclear energy sources can be used to generate the required heat. Solar thermal and geothermal power plants function according to the same thermodynamic cycle.

- Gas turbine power plants are based on the combustion of a gaseous fuel in the turbine. In the cold part of the turbine a gas/air mixture is compressed and fed to the combustion chamber. In the combustion chamber the fuel mix becomes ignited, producing high temperatures and pressures. In the hot part of the turbine the gas/air mixture expands and generates rotation that drives the generator. Depending on the pressures and temperatures, thermal efficiencies of up to $42 \%$ can be reached (known as the Carnot efficiency).

- Combined cycle gas turbines integrate the principle of gas and steam technologies. The exhaust gas from a gas turbine is fed into a waste heat boiler where it is used to produce steam, which is subsequently used to drive a steam turbine. Combined cycle power plants can reach fuel efficiencies of more than $60 \%$.

- Hydropower plants transform the kinetic energy from flowing water into rotational energy. Run-off-river plants use elevation differences of only a few meters, while the elevation difference of storage power plants can reach several hundred meters. Storage power plants use the potential energy of water collected in an (artificial) lake in the mountains only once. In contrast, pump storage power plants can use this energy several times. Water is collected in a lower basin and pumped back into an upper basin by using cheap excess power. While run-off-river plants produce 


\section{EPJ Web of Conferences}

electricity more or less continuously, storage and pumped storage power plants are used for interval and selective peak-load generation.

- Wind power plants use the kinetic power of wind in order to drive a generator. Like hydropower stations, they do not need fossil fuels and therefore have no greenhouse gas emissions. Their variable costs are also comparatively lower. However, the generation of these plants depends on the wind availability. The capacity factors of onshore wind turbines are usually below $30 \%$, while offshore wind installations can exceed capacity factors of $40 \%$.

- Photovoltaic power generation is based on the electrochemical transformation of sunlight into a direct current of electrons. An inverter is needed if the output must be alternating current $(\mathrm{AC})$. Like wind power, photovoltaics represents an environmentally friendly way of power generation, but this form of generation is again intermittent. The capacity factor of photovoltaics lies between 10 and $25 \%$. With growing shares of photovoltaic capacities, additional refinement concepts (e.g. batteries, load management) are required for satisfying electricity demand.

- Fuel cells produce an electron current by using electrochemical principles. One design option is the use of a hydrogen rich gas that flows over the anode and gives off electrons at the presence of a noble metal catalyst. Between the anode and the cathode is a proton-conducting membrane (Proton Exchange Membrane or PEM). Oxygen receives electrons at the cathode side of the cell and reacts with the proton to produce steam. As the operation temperature is below $100{ }^{\circ} \mathrm{C}$, the power generation of the fuel cell can be quite dynamic.

1`2. Power plant dispatch on day-ahead markets. - Under perfect supply competition a power plant operator looking to maximize profits will generate electricity as far as the (short term) marginal cost of the power plant is smaller than the market price he receives from selling the electricity. Otherwise, the power plant will not run and produce electricity. The formal analysis is quite simple. Assuming an individual supplier who maximizes its periodic profit

$$
\Pi(Q)=\bar{p} \cdot Q-C(Q)
$$

(difference between the periodic revenues $\bar{p} \cdot Q$ and the periodic $\operatorname{costs} C(Q)$ ) the solution is to be found by setting the derivative of the profit function with respect to the produced quantity $Q$ equal to zero:

$$
\frac{\mathrm{d} \Pi}{\mathrm{d} Q}=\frac{\mathrm{d}(p \cdot Q)}{\mathrm{d} Q}-\frac{\mathrm{d} C}{\mathrm{~d} Q}=\bar{p}-\frac{\mathrm{d} C}{\mathrm{~d} Q}=0 \rightarrow \frac{\mathrm{d} C}{\mathrm{~d} Q}=\bar{p} .
$$

In case of atomistic competition the individual producer cannot influence the sales price $p$ so that it is given: $p=\bar{p}$. Thus, the supplier should adjust the individual production $Q$ so that the marginal cost — the cost of the last produced unit — is equal to the fixed 


\section{LNES 2014}

sales price. If the marginal cost is smaller, the supply should be expanded, otherwise it should be reduced. Any sale at a price below the marginal costs is economically stupid.

Depending on the type of plant, marginal costs are the sum of several cost components:

- A large share of the marginal costs consists of the costs of fuels needed to generate one unit of electricity. There is a clear ranking of power plants using the same type of fuel. Growing fuel efficiencies lead ceteris paribus to lower fuel cost per unit of electricity produced. Thus, modern high efficient power stations have an advantage over older, less efficient facilities.

- Fossil fuels used for power generation are subject to the European system of $\mathrm{CO}_{2}$ emission allowances. The marginal cost of electricity generation depends on the quantity of $\mathrm{CO}_{2}$ emitted (in tons of $\mathrm{CO}_{2}$ ) when producing one MWh of electricity multiplied by the $\mathrm{CO}_{2}$ market price.

- If the output of thermal power plants falls below the optimal design point, efficiency losses occur and must be taken into consideration when calculating marginal costs.

- Thermal power stations need to be in operation temperature before being able to generate electricity. This determines turn-on and shut-off costs that belong to the marginal costs.

Competition between generators occurs on markets. The most important market is the day-ahead market. Products traded on this market are power deliveries for single hours of the next day as well as blocks of these contracts $\left({ }^{3}\right)$. The European Power Exchange EPEX offers the most liquid day-ahead market in Europe. It is a uniform price auction market. All bids and asks for an individual hour are collected and aggregated to an hourly supply and a demand curve. After gate closure, the energy exchange calculates the hourly market clearing price $(\mathrm{MCP})$, which is equivalent to the intersection of both curves.

The optimal supply strategy of each power plant operator is to offer electricity at (short term) marginal cost. In the aggregate supply curve all power plants are thus ordered according to their merit order. Figure 2 shows two wholesale market equilibriums, each describing a different demand situation. During off-peak hours (night and weekends) the hourly price is low, and only power plants with small marginal costs are dispatched, while the more expensive plants remain off-line. During peak hours additional and more expensive power plants (in terms of marginal costs) are required to cover the demand. Therefore the MCP is high.

Generators using renewable energy sources have rather small marginal costs (with the exception of biogas). If these generators would offer their capacities under competitive conditions and sell at their marginal costs, hydropower, wind and photovoltaic would

$\left(^{3}\right)$ While in Europe the day-ahead wholesale market is regarded as a spot market, the North American discussion defines this market as a future market. 


\section{EPJ Web of Conferences}

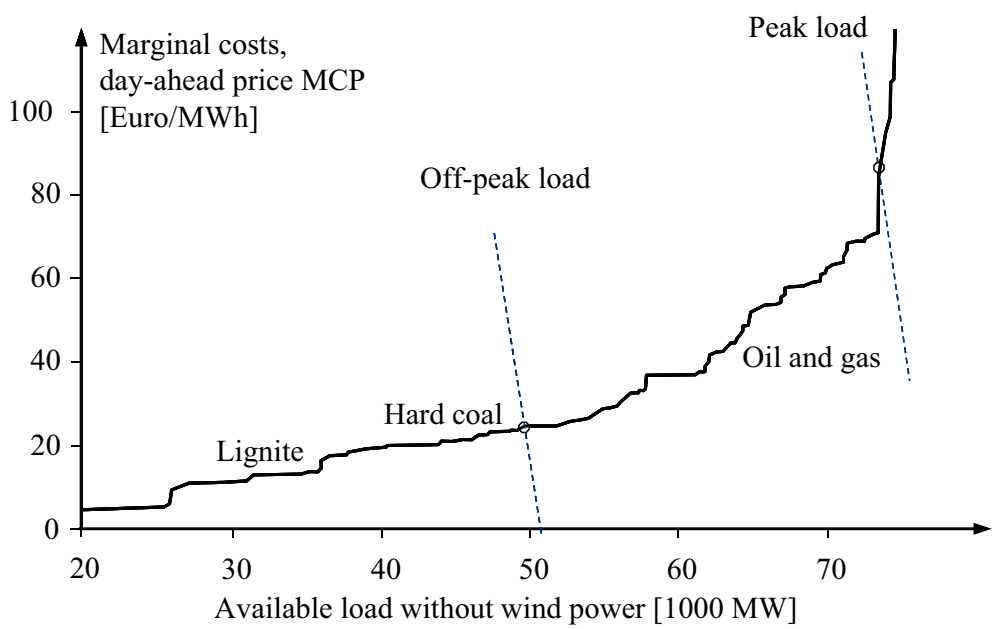

Fig. 2. - Merit order of power plants.

stand at the beginning of the merit order dispatch. If renewable electricity generation increases, the MCP will shrink below the marginal costs of thermal power generators, in particular gas fired power plants. This is the "merit order effect of renewables".

13. Intraday markets. - Because electricity cannot be stored, all market participants must close their open positions prior to each execution period (e.g. quarter hour intervals). Whether the positions are open or not is determined by generation and load forecasts. These forecasts depend on many parameters and must regularly be revised whenever new information is available, in particular when customers are lost or acquired.

A significant source of quarter hour forecasting errors is power generation from wind and photovoltaics. Even when using sophisticated forecasting models, the aggregated day-ahead forecast errors can exceed several thousand megawatts, if the cumulated share of these capacities is large $\left({ }^{4}\right)$. Hour-ahead forecast errors are much smaller. Intraday markets that allow trades up to an hour before execution (or less) can be used for closing deviations between day-ahead and intraday forecasts. Several intraday market concepts exist:

- Pool-type markets use the schedules and bids that have been submitted for dayahead scheduling to recalculate the optimal dispatch of power plants close to realtime delivery.

- Bilateral trade over an energy exchange without an institutional link to the dayahead market is the model applied in most European markets.

The liquidity of intraday markets is relatively small, particularly if it is organized as a continuous trade market. Still the observed intraday price volatility appears not to

$\left({ }^{4}\right)$ Average day-ahead wind forecast errors (RMSE) are presently in the range of 6 to $7 \%$. 
LNES 2014

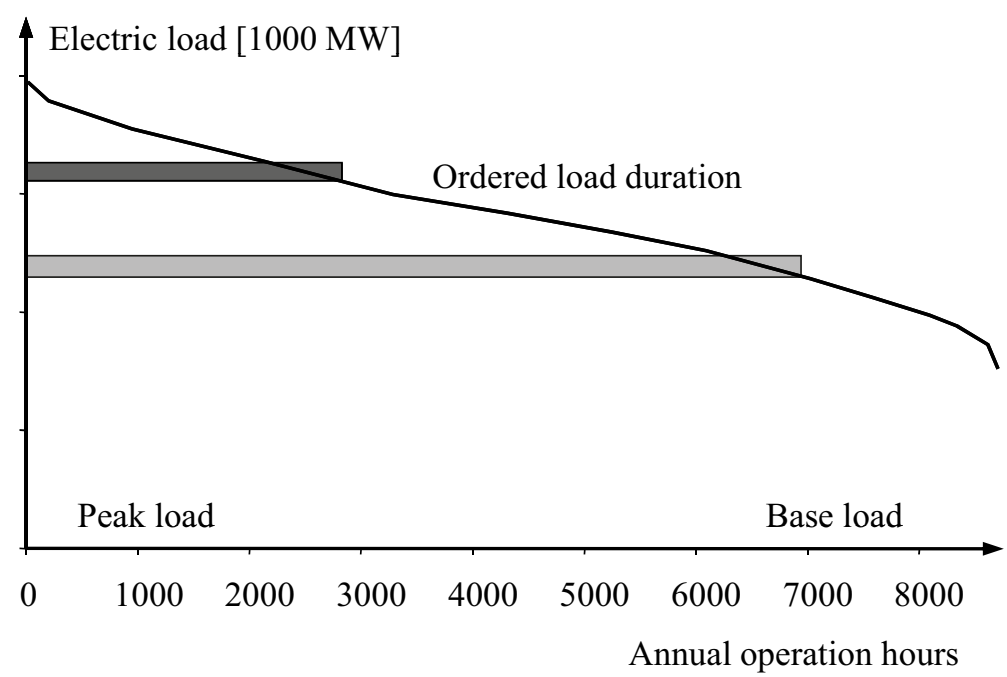

Fig. 3. - Planning of power plants under monopoly.

be excessive compared to the day-ahead price volatility. If more renewable electricity is offered than predicted in day-ahead forecasts, some power plant operators replace their generation by purchasing renewable electricity. If the renewable electricity generation falls short of day-ahead forecasts, conventional plants have to produce more. In both cases the marginal costs of the respective plant determines the intraday market price providing that this market is efficient. Imbalances that remain after gate closure of the intraday market are to be covered by the transmission grid operator in the corresponding control area. It delivers (positive or negative) balancing power as necessary which he has been purchased on the market for regulation power. The expected balancing power prices (real time price) should represent a limit for intraday prices.

\section{2. - Power plant investments}

Before the market liberalization in Europe, power generation was organized in closed areas without competition. Under these conditions investment planning is straight forward. First, the monopolistic utility has to forecast the ordered load duration for each year of the planning period (see fig. 3). The load duration orders all $24 \cdot 365=8760$ hours according to the expected load. The second step of the monopolistic planning process is to fill the area below the duration curve by rectangles that represent each available power plant. The height of the rectangle corresponds to the rated load. The length corresponds to the expected load factor. This reflects that some power plants are designed as peak load units with less than 3000 planned operation hours per year and others as base load units with more than 6000 planned annual operation hours. This planning step also takes into account power plants that will be retired during the planning period. If the area below the ordered load curves cannot completely be covered by the available power 


\section{EPJ Web of Conferences}

plants, including a predetermined reserve margin, additional power plants are needed. To finance the required investments, the regulator may allow power tariffs to increase. Regarding the high willingness to pay for electricity, the risk of declining electricity demand is moderate as long as the surcharge remains moderate.

To support regulators, the theory of optimal electricity tariffs was developed by economists including Botteux [1], Steiner [2] and Kahn [3]. The starting point is the marginal willingness to pay (WTP). A distinction is made between off-peak and peak demand. Deducting the marginal costs of electricity generation results in a WTP for capacity. Because generation capacity can be regarded as a public good, the WTP is horizontally (instead of vertically) aggregated in order to get the total marginal WTP for capacity. The optimal generation capacity is equal to the point in which the marginal cost for capacity (in particular capital uses cost, i.e. amortization and interest of the invested capital) is equal to the marginal WTP for capacity. With the optimal generation capacity the optimal power plant investment and capacity costs for both base load and peak load supply can also be determined. For the optimal capacity cost allocation to the two demand segments, regulators can use the Ramsey pricing model, which is equivalent to the optimal structure of grid fees.

One of the aims of electricity market liberalization is effective competition in the generation segment of the electricity value chain. Once competition is established the market determines optimal the power generation price. Thus the regulator should restrain from imposing Ramsey pricing on the generation industry and let the markets work without intervention. However electricity competition is organized, the grid always remains a natural monopoly and must be regulated. The theory of optimal regulation and Ramsey pricing remain relevant for the grid segment of the electricity value chain but not for the generation segment.

In competitive markets for power generation the availability of sufficient power plant capacities is a key condition for a safe and reliable electricity supply. Accordingly, incumbent generators should avoid investing into additional capacities, even if these capacities may be indispensable in the future. Once newcomers - independent power generators have the right to access the market they will invest into generation capacities if economic opportunities exist. In this case incumbents risk loss of market share if they abstain from investing in order to keep generation capacities short. Therefore, no systematical underinvestment should be expected if generation markets are competitive and market access is open.

Any power plant investment is economical if the expected cash flows or contribution margins exceed its capital expenditures. A deeper analysis is based on fig. 4, which shows the ordered price duration line of the (expected) hourly day-ahead prices in a particular year of the planning period. The expected annual operation hours of this year are determined by the intersection of the variable unit cost with price duration. The area above this point is equivalent to the annual cash flow. Clearly the investment is expected to be economical if time and price spikes occur because spikes contribute to the margin that is necessary to finance the capital expenditures of the plant. Should the regulator limit price spikes on the hourly power markets, sufficient generation investments cannot be expected. 


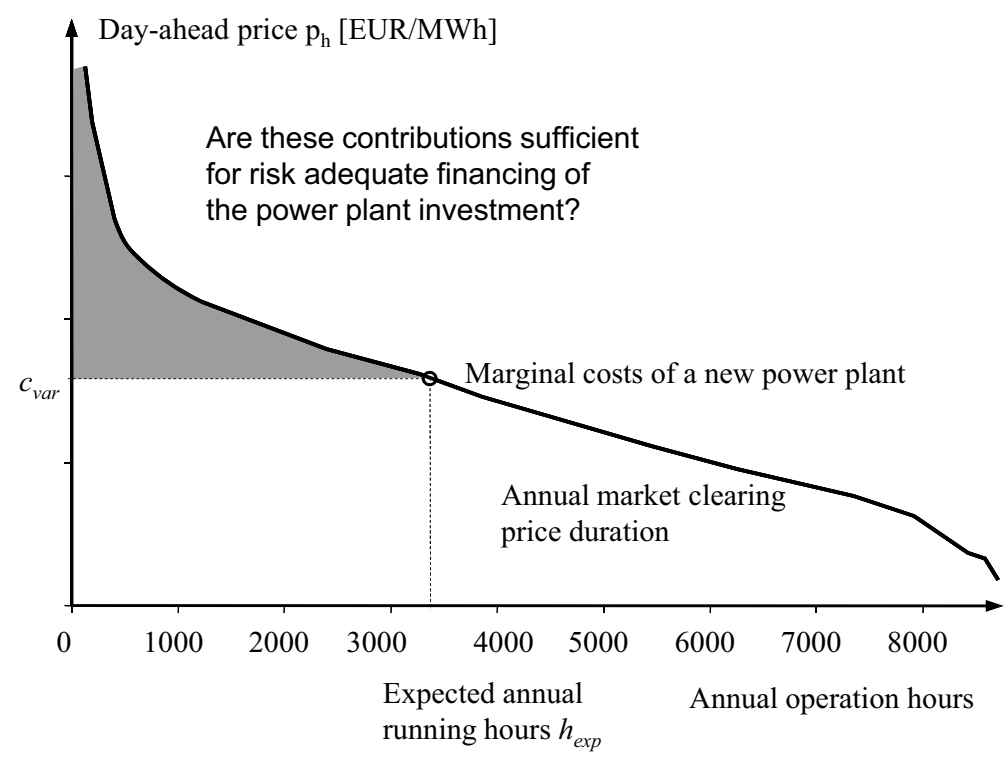

Fig. 4. - Merit order of power plants.

The day-ahead power prices vary from year to year. Therefore, the above calculation must be repeated for each year using the hourly price forecasts. To reflect the riskiness of the day-ahead prices, the distribution of the expected annual cash flows should also be included e.g. by Monte Carlo simulations. This leads to a probability distribution over the annual cash flows. The variable costs of the power plant, including mostly fuel costs and the price of emission allowances, can be secured by long-term contracts so that these price risks become irrelevant. Skipping this assumption, Monte Carlo simulations based on the expected distribution of fuel and $\mathrm{CO}_{2}$ prices are even possible.

On the other hand, power price risk could be hedged by power sales on forward and future markets. If the forward markets for electricity, natural gas, coal and emission rights are sufficiently liquid, the economic assessment of power plant investments can be based on the price signals from these markets. Therefore the following expressions have become popular:

- Spark spread for gas plants: the difference between the peak load electricity price future and the gas price future corrected by the fuel efficiency of the gas plant.

- Clean spark spread for gas plants: derived from the spark spread by subtracting the specific $\mathrm{CO}_{2}$ costs of gas power generation based on the future prices of emission rights.

- Dark spread for coal plants: the difference between the base load electricity price future and the coal price future corrected by the fuel efficiency of the coal power plant. 


\section{EPJ Web of Conferences}

- Clean dark spread for coal plants: derived from the dark spread by subtracting the specific $\mathrm{CO}_{2}$ costs of coal power generation based on the future prices of emission rights.

These spreads can be calculated for each year given a liquid forward/future market for which transparent prices exist. Otherwise, the spreads must be estimated by forecasting methods. Once the planner can estimate the clean spark (dark) spreads, he can assess the economics of a new gas (coal) power station by comparing the spreads with the annual capital and fixed costs of the plant.

An extension of this approach is based on the real options theory. According to this theory, a gas power plant can be regarded as a call option on the clean dark spread. Once the new capacity is available, their operators use this option whenever the clean dark spread is positive, namely by producing as much electricity as possible. The interpretation of power plants as real options implies that their value exceeds the value of the underlying (net present value of the cash flows) by an option premium. This option premium increases with the volatility of the cash flows and accordingly the expected volatility of the hourly spot prices. This again highlights the importance of spot market price spikes for power plant investment under competition.

It is reasonable to assume that a period of low plant investments would lead to tight electricity supply and thus higher spot and futures prices both in the base load and the peak load segment. The price increase creates an investment signal (once a threshold is passed) and ends the period of insufficient generation investments. However, one problem remains. If the lag between the decision to invest and the completion time of the investment is sufficiently short, the market mechanism should guarantee a stable, long term power supply $\left({ }^{5}\right)$. Otherwise, long term price fluctuations instead of a stable power price trend may result.

\section{3. - Capacity markets}

This raises the question as to whether or not the liberalized European electricity market is able to continuously secure the electricity supply by providing sufficient generation capacities. As electricity cannot be stored at significant volumes, a safe and reliable power supply requires some excess and reserve generation capacities. The excess capacities cover unexpected loads, while reserve capacities are required to back-up scheduled and unscheduled power plant outages. Some further generation capacity is required for supplying regulation power and other grid services, in particular redispatch of generation in case of grid bottlenecks. As a consequence, reserve margins of about $10 \%$ of the

$\left(^{5}\right)$ At the beginning of market liberalization, long-term power contracts had been an obstacle for benefits from liberalization to become real. Other than in the US, the European situation at that time was characterized by excess capacities so that planning for new investments was not an issue. Once this changes, long-term contracts are inevitable for power markets to efficiently generate power plant investments. The alternative would be state guarantees, subsidies or other types of market interventions. 


\section{LNES 2014}

maximum load are usually assumed to be necessary to secure electricity supply at any time (system adequacy), but this reserve margin may not be offered in the regular power market. Mechanisms must therefore be installed to finance the reserve margin.

In a market with a single generator the regulator requires the monopolistic utility to secure the necessary excess and reserve capacities and allows their financing through electricity tariffs. Competitive markets will not automatically provide appropriate capacities because supply security has the character of a public good. With the implementation of electricity market competition the regulators have developed several mechanisms in order to solve this problem:

- The regulated Transmission System Operator (TSO) purchases capacities that are needed for supplying balancing power. The plant operators receive capacity payments determined by pay-as-bid auctions.

- In a fully liberalized market with retail competition each wholesale market participant (balancing group managers), in particular each retailer, has to purchase balancing power from the TSO to adjust for imbalances between supply and demand in its balancing group. If the imbalances are excessive, the regulator may impose a fine. In extreme situations the TSO can even prohibit the balancing group manager from using the grid.

- Over-the-counter capacity markets exist that provide back-up power, for example in cases of plant outages. The demand comes, among others, from the operators with a small portfolio of generation plants.

- In some countries regulators purchase emergency capacities that are released if the power system threatens to fail. The regulator may organize a public auction to acquire appropriate capacities and decides about the conditions under which these capacities should be released. Because emergency capacities cannot participate in the regular day-ahead market, this mechanism increases the regular wholesale power prices, but when the emergency capacities are released, the peak prices come under pressure. Obviously, the criterion for releasing emergency capacities determines the maximum hourly price. State intervention thus can reduce the incentives for private power plant investments.

The situation of capacity shortages can be explained by the simplified merit order function shown in fig. 5. Point $A$ shows a regular market situation in which the marginal costs of the last available power plant (i.e. excluding the reserve margin) sets the market clearing price $p_{1}$. All power plants to the right of the marginal plant also receive the price $p_{1}$ and earn infra-marginal rents above their marginal costs. The last unit in the merit order has marginal costs of $p_{2}$. If all available power plants together are not sufficient to cover the total demand, the market clearing price will spike to $p_{3}>p_{2}$ leading to a capacity surcharge. The price difference $p_{3}-p_{2}$, is also called "capacity rent".

If such situations would happen regularly, the capacity rent would stimulate generation investments. It is important to note that in point $B$ of fig. 5 the power price is above 


\section{EPJ Web of Conferences}

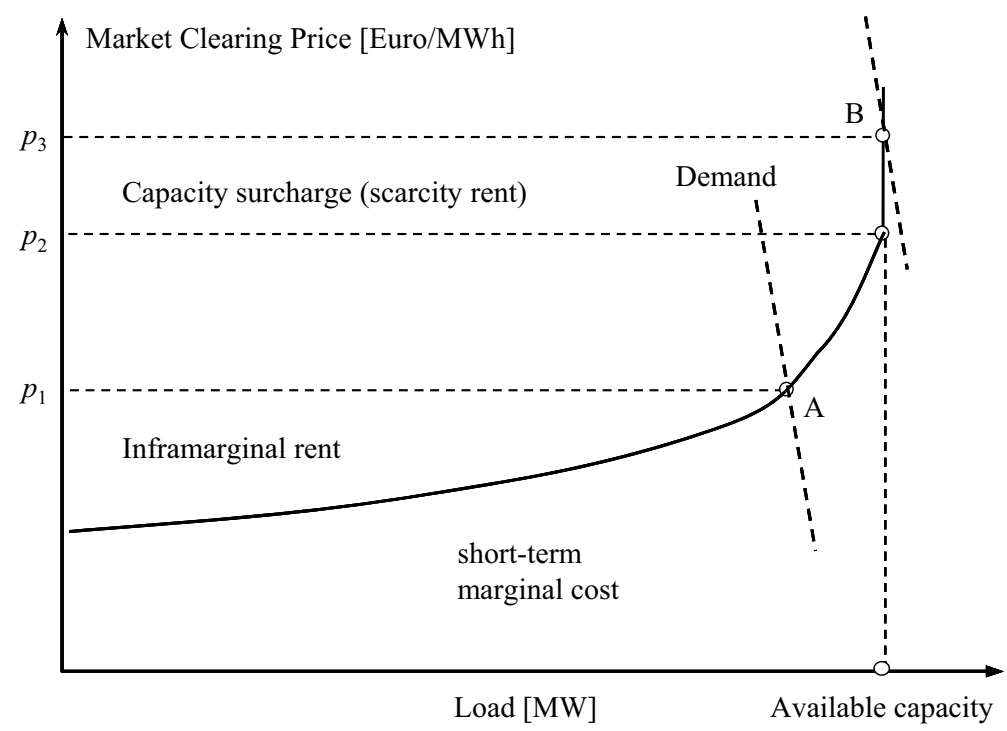

Fig. 5. - Electricity market under capacity shortage.

the marginal cost of any plant in the merit order, but still this situation is not the result of misusing market power. In liberalized markets the wholesale power price can, and must from time to time, exceed the marginal costs. But due to the public involvement (suspicion that generators manipulate market prices and obtain excessive returns) the regulator may come under political pressure to intervene in favor of lower power prices. Thus, for political reasons the energy-only market may not generate sufficient revenues for financing power plant investments - the so-called missing money problem. To correct for this problem, capacity payments to (certain) power generators are proposed, that are financed outside the energy-only market by a capacity levy imposed on (all) final electricity consumption.

Alternatively, a decentralized capacity market design is possible. Retailers and eligible industrial customers must hold capacity certificates before they can purchase electricity at the wholesale market. Generators, electricity storage operators and customers with interruptible loads are on the supply side of the decentralized capacity market. The capacity price is the result of supply and demand and will be high in periods with tight capacities (weak renewable electricity supply), but it can also be zero if sufficient capacity is available (strong renewable electricity supply). Such a decentralized market requires again an institution that supervises and controls the behavior of market participants, but there is no central planner who determines the necessary capacity as would be the case under centralized capacity mechanisms.

In power systems with high shares of intermittent renewable energy sources another concept could be implemented. This concept is based on the customer's choice to select the desired quality of electricity supply. A regular power supply contract could allow 
the retailer to cut the supply during one or more hours per day if capacities are short (usually during evening hours). Electricity customers can opt for a non-interruptible power supply but they have to pay for the individual cost associated with this service. The expectation is that such a concept would initialize a variety of innovations so that the final result will be cost savings compared to capacity markets with politically planned generation (or electricity storage) investments.

\section{4. - Power market design options}

Before liberalization, electricity markets had usually been organized in closed concession areas in which the state regulator allowed only one single company to distribute electricity. These local or regional distributors were allowed to sign long-term and fullservice electricity agreements with upstream power generators. According to these contracts, utilities had the exclusive right to deliver electricity to the distribution company in the concession area, but without directly supplying final electricity users. As a result, all final users were obliged to purchase electricity from a single distributor, and no competition between generators was possible. In return distributors were not allowed to refuse any customer asking for electricity supply. Additionally, electricity prices above regulated tariffs were not allowed, but large industrial customers could benefit from special power purchase agreements at prices below the regulated tariff.

When implementing competition, the first observation is that a vertically integrated utility industry does not necessarily represent a natural monopoly. This has first been shown by Christensen and Greene [4] in the USA. According to their study, economies of scale exist, but with regard to the already achieved size of the power market unit costs of vertically integrated companies cannot shrink further if output levels continue to grow. Similar results have later been found by Thompson and Wolf [5]. Only the transmission and distribution part of the electricity value chain represent a natural monopoly. Liberalization should therefore focus on the other parts of the value chain, in particular generation, trade and marketing, and regulate the electricity grids so that competition among generators and (eventually) distributors becomes possible.

Guided by these principles, several market design options are possible (see $[6,7])$ :

- Single-buyer market: All generated electricity has to be offered to a centralized (usually government managed) pool, the single buyer. The pool operator calculates the cost optimal dispatch so that the aggregated load is always covered by the least expensive combination of available power plants. As is the case under regulation, retailers and eligible customers have no alternative to buying electricity from the pool. No company can purchase power through bilateral contracts. This helps incumbent retailers to keep their monopolistic market position, but if the retail market is legally opened for newcomers, this market is contested and tariff control can be abandoned. Supply side regulation is necessary as generators may manipulate their offers. The pool operator can also allocate side payments in order to stimulate investments into operating reserves. 


\section{EPJ Web of Conferences}

- Mandatory power pool: All generators must offer the generated electricity to a centralized pool. This model functions like an energy exchange as retailers and eligible customers can also submit individual bids to the pool in order to satisfy their power needs. The bids are based on the load forecast and can reflect demand side strategies and auto generation strategies. As forecasting errors are unavoidable, a separate balancing mechanism must be in place. The pool calculates the market clearing price, which is relevant for all buyers and sellers. Again, manipulation of generators can occur so that price regulation is necessary.

- Free wholesale competition: Power can be traded through bilateral long term contracts (forward and future contracts with physical delivery) and through an energy exchange. This model offers more options to generators and retailers and is therefore more efficient. However, the voluntary participation at the energy exchange leads to a reduced liquidity and increased efforts for controlling the non-distorting behavior of generators are necessary.

- Fully liberalized market with retail competition: This is the most sophisticated model of liberalized electricity markets. In addition to the power exchange, all types of bilateral power trades are allowed. Generators and retailers can develop and apply a manifold of contract models (portfolio management). The establishment of this system takes usually several years but can then work quite efficiently. In particular new retail companies have a chance with innovative products that beat the retail market price. But as retail margins are quite small, many authors argue (e.g. [6], p. 26ff, [7], p. 713ff) against the benefits of retail competition. However, the European Electricity Market Directives 96/92/EC, 2003/54/EC and in particular 2009/72/EC require the implementation of this model in Europe (see [8]).

\section{REFERENCES}

[1] Boiteux M., J. Business, 33(2) (1956) 157.

[2] Steiner P. O., Q. J. Econ., 71(4) (1957) 585.

[3] Kahn A., The Economics of Regulation (MIT Press, Cambridge, MA) 1970.

[4] Christensen L. R. and Greene W. H., J. Polit. Econ., 84 (1976) 655.

[5] Thompson H. G. jr.and Wolf L. L, Land Econ., 69 (1993) 234.

[6] Sтоғт S., Power System Economics. Designing Markets for Electricity (Wiley, New York) 2002.

[7] Bhattacharyya S. C., Energy Economics. Concepts, Issues, Markets and Governance (Springer, London) 2011.

[8] EU-Commission: Directive 2009/72/EC of the European Parliament and the Council of 13 July 2009 concerning common rules for the internal market in electricity and repealing Directive 2003/54/EC, Official Journal of the European Union L 211/55-93 (2009). 